\title{
¿Políticas públicas o acciones de gobierno turísticas en Ixtapan de la Sal? \\ El caso del Cocdetur
}

\author{
Graciela Cruz Jiménez
}

Investigación financiada por CONACYT

\begin{abstract}
RESUMEN
Los cambios en la forma de gobierno en México han impulsado, al menos en teoría,alas políticas públicascomoun mecanismopara propiciarlaparticipación de los distintos sectores de la sociedad en su diseño, implementación y evaluación, contrario a las tradicionales acciones de gobierno, asumidas en solitario por la autoridad pública. El Consejo Consultivo de Ixtapan de la Sal (Cocdetur) se erigió como un órgano de consulta tendiente a incorporar los principios de las políticas públicas a la conducción de la actividad turística. Este artículo pretende determinar si se cumplieron estos propósitos o se mantuvo el esquema tradicional. Con base en ello, las condiciones sustentables o no que propicia una u otra en la comunidad receptora.
\end{abstract}

PALABRAS CLAVE

Turismo, políticas públicas, gobierno municipal. 


\title{
Public policies or tourist government actions in Ixtapan de la Sal? The Cocdetur case
}

\author{
Graciela Cruz Jiménez
}

Investigación financiada por CONACYT

ABSTRACT

The changes in the forms of government in Mexico have launched, al least theoretically, the public policies as a mechanism to propitiate the participation of different sectors of society in its design, implementation and evaluation; contrary to the traditional actions of government assumed in solitary for the public authority. The CODECTUR (Consult Council of Ixtapan de la Sal) was founded as an consult organism which tends to incorporate the principles of public policies to the conduction of the tourist activity. This article intends to determine if the aims were fulfilled or if the traditional scheme remained. Based on that, it also intends to determine the sustainable conditions or none which one or the other cases propitiate onto the receptive community.

\section{KEY WORDS}

Tourism, public policies, municipal government. 


\section{INTRODUCCIÓN}

El rumbo de la vida económica, política, administrativa, social, cultural y ambiental de una nación, estado, municipio y/o localidad es definido en gran medida por las políticas públicas -traducidas en programas y acciones- que se apliquen en ellos. Por su parte, la actividad turística cobra nuevas dimensiones según la política pública que la oriente, que en consecuencia propicia condiciones sustentables o no para la comunidad receptora, entendida como el espacio físico (la localidad) y sus habitantes.

El contenido de este artículo está basado en las políticas públicas como aquellas líneas de acción que engloban la atención de necesidades, proyectos e intereses generales y la corresponsabilidad entre gobierno y la sociedad para apoyar estos propósitos, mediante los cuales se pretende acercar a valores como la democracia y la pluralidad (Bazúa y Valenti; 1994:51-52).'

Es importante establecer desde este punto -aunque se ahonda en ello más adelante- que la condición pública de estas políticas, no significa que lo sean sólo porque una autoridad pública² las concrete, sino por sus amplios

Graciela Cruz Jiménez

Maestría en Estudios Socioeconómicos y físicos del turismo, UAEM.

Reportera, corresponsal, jefa de información y colaboradora en diarios locales y nacionales.

Analista, Coordinación General de Comunicación Social, Gobierno del Estado de México, 2001-2007. alcances -algunos de ellos referidos en el párrafo anterior- y porque es, o debe ser, el sector público quien incorpore a los sectores social y privado a concretar acciones encaminadas a la atención de un problema que amerite la intervención de la sociedad en su conjunto.

De acuerdo con Aguilar (1992:33-36) y Merino (2000:118), cualquier política o decisión tomada por el gobierno que propicie de alguna forma la participación de la sociedad, o la simple decisión deliberada del actor gubernamental, no deben ser confundidas con políticas públicas. Méndez (1993:90, 1994:37) advierte que no todas las acciones estatales representan políticas públicas, ya que éstas se relacionan con un problema público, al diagnóstico sobre las causas del problema y a las medidas para resolverlo o mitigarlo. 
De ahí que el presente artículo esté centrado en analizar si el Consejo Consultivo de Desarrollo Turístico (Cocdetur), una de las principales acciones en la materia (correspondiente a la administración municipal 2000-2003) obedeció a una mera acción de gobierno, o en realidad respondió a un proceso de políticas públicas en que representantes de los distintos sectores tuvieran una participación equilibrada y equitativa en la definición de las estrategias turísticas, como al menos en teoría fue el propósito de las autoridades ixtapenses, de incorporar a los distintos sectores de la sociedad a este Consejo (Gaceta Municipal, 2000:9).

La creación de dicho órgano de consulta se dio además en un contexto en el que presuntamente el gobierno de Ixtapan de la Sal ya habría tenido la oportunidad de asimilar e incorporar los cambios que se gestaron en las administraciones municipales durante los ochenta, a raíz de las reformas al artículo 115 constitucional, que otorgaron a esos órdenes de gobierno mayores facultades para orientar su desarrollo.

Paralelamente durante esa década, como ha sido expuesto en diversos espacios, emergió el concepto de sustentabilidad que ha sido aplicado a distintos ámbitos, uno de ellos el turístico. En términos generales y con base en la amplia discusión sobre el tema, el turismo debe ser sustentable en lo ecológico, social y económico, con lo cual desempeñaría un rol importante dentro del desarrollo de la localidad donde tenga lugar dicha actividad, en beneficio de su población (OMT; 2002:9).

Para ahondar sobre el propósito del artículo, en el siguiente apartado se brinda un panorama sobre los principales postulados de las políticas públicas, el cual sirve como marco para analizar si el Cocdetur estuvo apegado a dichos postulados, o si respondió sólo a la tradicional acción gubernamental. Para contextualizar el contenido, se presentan también los antecedentes de 
la actividad turística en Ixtapan de la Sal y sus principales actores. En las conclusiones se examina el papel del gobierno municipal en las distintas fases de este órgano de consulta y su reconversión en una nueva figura.

Parte importante del contenido está basado en los testimonios recabados mediante entrevistas a profundidad con los participantes de la actividad turística en Ixtapan de la Sal: prestadores de servicios y autoridades, cuyos puntos de vista permitieron contrastar, corroborar o descartar aspectos que se daban como ciertos en otro tipo de fuentes, y que posibilitaron acercarse a lo que viven a diario los protagonistas del turismo. ${ }^{3}$ 


\section{EL SUSTENTO DE LAS POLÍTICAS PÚBLICAS}

Durante los ochenta, en México empezaron a surgir transformaciones en lo político y económico como resultado de aspectos como las demandas sociales de democratización (Aguilar; 1992:16) o el propósito del Estado por legitimarse ante la sociedad frente al desgaste y descrédito que sufrió debido a los excesos de todo tipo cometidos durante su ejercicio del poder (Rodríguez; 1999:42; Meyer; 1994:243). Con ello inició un cambio en la manera de elaborar las políticas públicas en que fueron incorporados los sectores privado y social, con lo que el sector público dejó de ser el protagonista de esta acción.

Se ha reconocido ampliamente (Merino; 2000:40; Meny y Thoenig; 1992:103; Méndez; 1993:90 y 1994:37; García; 1994:30, entre otros) que una política ya no puede depender sólo de la autoridad y que para ser en verdad pública debe serlo desde su origen, incorporando a los sectores social y privado, alentando con ello la acción corresponsable (Aguilar; 1992:33). A su vez, los principios de estas políticas establecen el vínculo que debe existir entre el gobierno con los actores sociales y privados a partir de la atención de necesidades, proyectos e intereses de alcance general, que incluya la toma de decisiones conjuntas durante el proceso de tales políticas.

Incluso Bazúa y Valenti (1994:52) advierten que por los inmensos poderes que detenta y por serlo, la autoridad jurídicamente pública puede ocuparse de problemas privados o de dudosa publiceidad ${ }^{4}$ y ejecutar políticas diseñadas para satisfacer interesada o dolosamente, intereses privados, con grave prejuicio del interés público. Es por ello que Merino (2000:118) resalta que una política debe estar diseñada por quienes han de participar en su ejecución, transparente en el momento de implementarse, y nítidamente responsable de los recursos que empleen, tanto el gobierno como la sociedad.

Por lo tanto, Cabrero (2000:193; 2003:17) advierte que lo público de las políticas significa, sobretodo, el encuentro de la racionalidad estatal con la voluntad social; es lo público como intersección, como un espacio de confluencia entre actores gubernamentales y no gubernamentales. Justamente por su carácter público, Aguilar (1992:32) destaca que su análisis y diseño abre todo un abanico de estrategias de acción corresponsable entre gobierno y sociedad; que pueden englobar al sector privado, a las organizaciones no gubernamentales, a organismos 
internacionales y a las organizaciones sociales de los directamente interesados en encontrar una solución a su problema.

Por ello, Aguilar (1992:33-36) hace énfasis en que gobernar de acuerdo con política pública significa incorporar la opinión, la participación, la corresponsabilidad, el dinero de los ciudadanos y en esa perspectiva disminuye el solitario protagonismo gubernamental, por lo que aumenta el peso de los individuos y de sus organizaciones; se sustancia ciudadanamente al gobierno y se abren de par en par las puertas para nuevas formas de diseño y gestión de las políticas: singulares, descentralizadas, subsidiarias y solidarias, corresponsables, en las que el gobierno y sociedad enfrentan variada y conjuntamente los problemas colectivos. Uno de sus principios más importantes de las anteriores exposiciones es que lo público representa para los gobiernos su referente de legalidad y legitimidad, por tanto el gobierno de lo público da cabida a las políticas públicas (Uvalle; 1997:42, 47).

En lo que respecta al turismo, al mismo tiempo que tenían lugar los referidos cambios en el contexto nacional, el gobierno federal impulsaba el turismo doméstico, con el propósito de que los residentes visitaran su propio país y por lo tanto se re-orientó la oferta para satisfacerlo. Como producto de tal tendencia empezaron a cobrar mayor importancia las localidades como espacios turísticos, pero no como un hecho aislado, sino como parte de una serie de acciones, entre ellas la reforma constitucional al artículo 115 a principios de los ochenta, mediante la cual estos ámbitos de gobierno tuvieron mayores posibilidades de intervenir en su propio desarrollo. Con ello, según Lickorish y Jenkins (1997:198) inició un cambio en la práctica tradicional, en que la política y planificación dependían sólo de los gobiernos.

En el caso del turismo, como se mencionó, al ser implementadas dichas líneas de acción definen cierto modelo ${ }^{5}$ que genera implicaciones derivadas de su puesta en marcha, algunas de ellas estrechamente vinculadas con los principios de la sustentabilidad. Por lo tanto este artículo se ocupa de establecer si en realidad las acciones implementadas en torno al Cocdetur estuvieron apegadas al espíritu que rige a las políticas públicas: abiertas, corresponsables, equitativas y democráticas, entre otras características de las ya referidas, y si éstas propiciaron condiciones sustentables en la comunidad. 


\title{
ANTECEDENTES
}

Ixtapan de la Sal es un municipio asentado en el sureste del Estado de México que pertenece a la región VI de Coatepec Harinas. Limita al norte, con los municipios de Villa Guerrero y Coatepec Harinas; al sur, con Tonatico, Zacualpan y con el Estado de Guerrero; al oriente, con Villa Guerrero y Zumpahuacán y al poniente, con Coatepec Harinas y Zacualpan. La distancia aproximada a la ciudad de Toluca, capital del estado, es de 84 kilómetros por la carretera federal número 55, que interrelaciona la zona con las ciudades de Toluca y Taxco, Guerrero; y Cuernavaca, Morelos. Ver mapa.

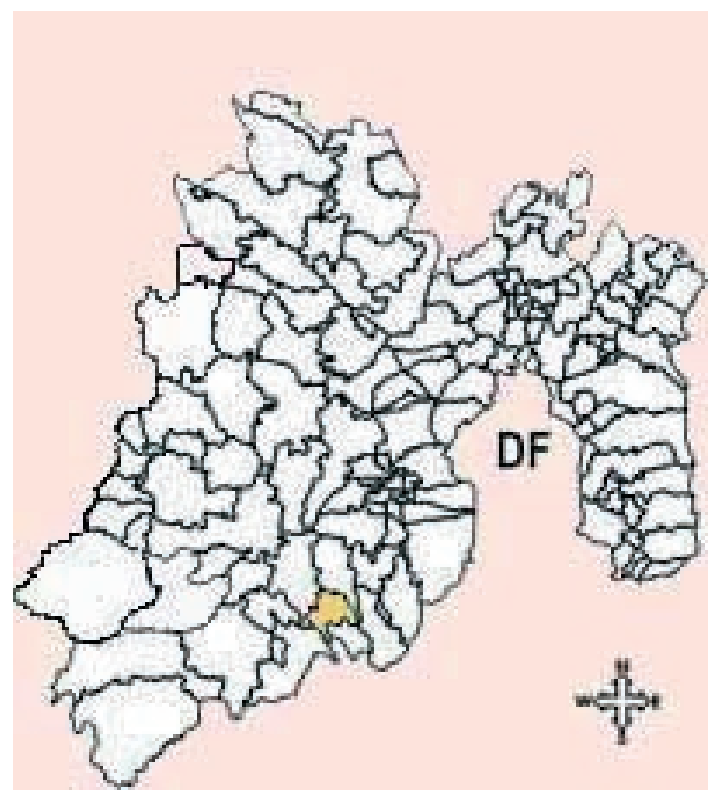

\author{
Ubicación del municipio \\ de Ixtapan de la Sal en \\ el Estado de México
}

Su clima predominante, semicálido, subhúmedo con lluvias en verano y una temperatura media anual de $17.9^{\circ} \mathrm{C}$, es una de las características naturales que ha tenido especial impacto en su desarrollo turístico, pues se le considera "agradable para la salud y el descanso" (Arizmendi; 1999A:17). Asimismo, por su relieve, dispone de una gran variedad de especies vegetales (Flores; 1987; 21-23) visualmente atractivas, e integran el paisaje que representa parte de la oferta 
turística. Sin embargo sus aguas termales con propiedades curativas son las que han posicionado a esta localidad como un centro turístico por excelencia y como un polo de desarrollo del sur del Estado de México, aunado a su ubicación territorial en el centro del país e importante número de establecimientos turísticos (Plan Municipal de Desarrollo 2000:28; Plan Municipal de Desarrollo 2003:53). ${ }^{6}$

La afluencia anual promedio en Ixtapan de la Sal es de 2'073,503 personas; $94.1 \%$ de ellas nacionales y $5.9 \%$ extranjeros. La comunidad centra su desarrollo económico y empleo en torno a la prestación de servicios turísticos, ya que la principal fuente de ingresos proviene del sector terciario7 (PMD; 2003:53), el cual de 1990 a 2000 cobró especial relevancia en la cabecera municipal respecto a las dos décadas anteriores. El turismo beneficia a $73 \%$ de la población de la cabecera municipal, pues $26 \%$ tiene empleos regulares vinculados con este rubro y $47 \%$ se beneficia indirectamente por medio del comercio y otras actividades asociadas (Martínez; 1997:35), incluidas las empresas constructoras y la micro industria (González; 2004:3), así como artesanía, servicios de esparcimiento y culturales, además del transporte, entre otras (Ricaurte; 2001:105).

El perfil turístico de esta localidad se fue delineando con el paso de los años. Desde la época colonial tuvo un papel estratégico dentro de la Provincia de la Plata ${ }^{8}$ por su cercanía con la ciudad de México y con las minas de Zacualpan y Tasco (García; 2000:53-54). Pese a ello sólo era un lugar de paso y de descanso para los comerciantes; fue hasta la segunda década del siglo XX que empezaron a sentarse las bases que contribuyeron a moldear su actual orientación como destino turístico, esto, gracias a la popularidad que obtuvo por el aprovechamiento de sus aguas termales, a partir de lo cual se consolidó su infraestructura turística.

El hecho determinante que marcó el despegue de este sitio fue la concesión de los borbollones de San Gaspar que en 1947 otorgó el gobierno federal al empresario forestal Arturo Alfredo San Román Chávez, quien ejerció su poderío económico y político a fin de obtener tal beneficio, a partir de los cuales erigió un spa mediante el cual alentó el turismo de salud. En su momento dicha concesión generó la oposición de pobladores y pequeños hoteleros, la cual persistió con el 
paso de los años. Similar situación se registró cuando hacia los sesenta, la empresa Nueva Ixtapan (NISA), propiedad de San Román Chávez, resultó favorecida como la principal concesionaria de agua de riego. ${ }^{9}$

Dicho descontento se explica porque en 2005 NISA recibía 158.7 litros por segundo (Ips), mientras el gobierno municipal obtenía sólo 16.2 lps, ante lo cual funcionarios locales y partidos políticos manifestaron su preocupación de que los San Román, como se conoce a esa familia en la comunidad, tuvieran el control casi total del agua y no el gobierno municipal al que prácticamente tienen sometido, ya que condicionan el suministro a la población para afianzar su poderío económico y político, independientemente de que la disposición de este recurso les garantiza el funcionamiento de sus diversas instalaciones.

Al paso del tiempo, los hijos y nietos de Arturo San Román Chávez consolidaron y prácticamente monopolizaron la oferta turística gracias a la posesión del Parque Acuático Ixtapan de la Sal que representa actualmente el principal atractivo- el club de golf y fraccionamiento turístico residencial Gran Reserva, el Hotel Ixtapan, el fraccionamiento Residencial Ixtapan y al renovado spa. Esto, además de empresas de otro tipo ajenas a este rubro, como constructoras y escuelas, entre otras.

Tras la muerte del patriarca, su hijo Arturo San Román Widerkehr reactivó en los ochenta el Parque Acuático Ixtapan de la Sal hasta convertirlo en uno de los 10 más importantes en el ámbito internacional y número uno en México por sus juegos de nueva generación y tecnología de punta (varios de ellos únicos en el mundo) ${ }^{10}$ lo cual representó un elemento determinante en el cambio de la orientación turística, ya que entre otros aspectos influyó para modificar el perfil del visitante de manera cualitativa y cuantitativa, ya que de permanecer durante largos periodos (en particular los turistas extranjeros), se dio paso a una afluencia masiva de usuarios, especialmente nacionales, con lo que se redujo el número de turistas y su estancia (RDE, 2005; JCSBR, 2005; JMH, 2005).

Ixtapan de la Sal, además de los referidos servicios a cargo de los San Román, tiene 1,421 habitaciones correspondientes a tres hoteles de cinco estrellas; 1 de cuatro; 10 de tres; cinco de 
dos y tres de una estrella, además de 23 posadas familiares; tres hoteles de clase económica y ocho de ellos sin clasificación, que en conjunto suman 56 establecimientos. Asimismo dispone de 38 establecimientos de alimentos y bebidas y dos agencias de viajes (Secretaría de Turismo, 2005). ${ }^{11}$

Las dos agrupaciones con que cuenta son la Asociación de Hoteles y Moteles de Ixtapan A.C (AMHM) y la Asociación de Prestadores de Servicios de Ixtapan (ASPI). La primera de ellas concentra básicamente a hoteleros de mediana categoría y la segunda tanto a empresas de los San Román, como establecimientos de giros ajenos al turismo. Los integrantes de ambas se vincularon estrechamente en el Consejo Consultivo de Desarrollo Turístico, creado en 2000. 


\section{ANTECEDENTES}

En el Estado de México entró en vigor en julio de 1996 el Impuesto sobre la prestación de servicios de hospedaje, como resultado de un acuerdo nacional entre dirigentes de prestadores de servicios turísticos con la Secretaría de Turismo (Sector) para promover la creación en todo el país de este gravamen destinado a impulsar el turismo. ${ }^{12}$ Dicha medida provocó inconformidad entre un amplio sector de los hoteleros ixtapenses que en su mayoría consideraban alta esa carga impositiva. Para atender esta situación, el gobierno municipal 2000-2003 propuso a los prestadores de servicios y a la sociedad en general, la creación del Consejo Consultivo de Desarrollo Turístico de Ixtapan de la Sal. ${ }^{13}$

Las autoridades justificaron su puesta en marcha para proponer "una política de firme aliento a la participación ciudadana y de sus organizaciones civiles en las diversas tareas de la administración pública municipal" (PMD, 2000:72-73). Conforme a la Ley Orgánica Municipal (1993), a estos Consejos se les concede, entre otras, las atribuciones de promover la participación ciudadana para realizar programas municipales, coadyuvar al eficaz cumplimiento de los planes y programas aprobados por el Ayuntamiento, proveer las acciones tendientes a modificar éstos; participar en la supervisión de servicios públicos e informar periódicamente a sus representantes y al Ayuntamiento sobre sus proyectos y actividades realizadas.

El propósito esencial de la conformación del Cocdetur fue:

“...crear un órgano de consulta del $\mathrm{H}$. Ayuntamiento que tenga como objeto primordial analizar, discutir y proponer obras y acciones relacionadas con la ampliación y mejoramiento de la infraestructura turística del municipio, susceptibles de ejecutarse con los recursos provenientes del Impuesto sobre Hospedaje". Sus atribuciones son deliberar y proponer al $\mathrm{H}$. Ayuntamiento la adopción, modificación y eliminación de disposiciones de la reglamentación municipal y del Bando de Policía y Buen Gobierno, relacionados con la actividad turística: promover, apoyar y organizar eventos artísticos, culturales, deportivos y recreativos que tengan por objeto incrementar la afluencia turística en el municipio; analizar y sugerir acciones relacionadas con la imagen urbana. Además, proponer al cabildo acciones que contribuyan a mejorar los servicios de hospedaje, comida, transporte, seguridad y diversiones en general (Gaceta Municipal, 2000:9). 
De habérselo propuesto, el entonces alcalde Ignacio Rubí Salazar pudo haber retomado los referidos principios establecidos en la Ley Orgánica Municipal sobre las atribuciones que se concede a los Consejos para promover la participación ciudadana en la realización de programas municipales y participar en su supervisón, entre otras, pero no lo hizo así, lo cual generó una serie de inconformidades. La primera de ellas es que no estuvo claro para la mayoría de los hoteleros, quiénes y cómo decidieron qué prestadores de servicios integrarían el Consejo, lo cual afectó la relación con el Alcalde.

Este órgano de consulta estuvo formado por 13 vocales. Es de resaltar que a pesar del voto de calidad que se le concedía al Presidente municipal, el sector público tenía entonces sólo cuatro representantes y el privado nueve; tal desequilibrio alentó el predominio de este último sector en la toma de decisiones al interior del Consejo que no incluyó la participación de organizaciones civiles como lo establecía la justificación para crear ese tipo de Órganos; aunque, como se plantea más adelante, finalmente tal hecho, más que beneficios, afectó a los propios empresarios.

Otro aspecto a destacar, es que si bien el Acuerdo por el cual se creó el Cocdetur señalaba que siete de sus vocales eran prestadores de servicios de hospedaje de distintas categorías, en realidad tres de ellos pertenecían a establecimientos de cinco estrellas y cuatro a los de tres estrellas, con lo cual quedaron relegados representantes de los hoteles de dos y una estrellas, así como las posadas familiares. Se infiere que esta exclusión se debió a su escasa contribución al impuesto sobre el hospedaje, pues fácilmente pueden evadir su cumplimiento porque no manejan sistemas de facturación automatizados, contrario a los grandes hoteleros.

La misma situación se repitió en la descripción de este programa para ser evaluado en el Premio Anual 2001 de "Gobierno y Gestión Local" del Centro de Investigación y Docencia Económicas (CIDE); el entonces Alcalde reportó que estaban representados todos los prestadores, lo cual provocó el descontento de los pequeños al haber sido excluidos. Entre otras razones los inconformes aludieron caciquismo, escaso margen de actuación de las autoridades municipales e imposición de la familia San Román que forzó el ingreso del restaurantero Eduardo Beltrán, actor cercano a Roberto San Román Dunne, heredero del Hotel Ixtapan. Similar malestar generó la 
inclusión del parque acuático, a cargo de Arturo San Román Moore quien fue incorporado "como apoyo" a los acuerdos de su primo. El descontento estuvo centrado en que ambos personajes no debían pertenecer al Cocdetur, ya que no tenían ninguna relación con el referido impuesto, pero sí con los San Román (IAE, 2005; LRDA, 2005; HHP, 2005).

En medio de esta situación, en la primera sesión del Cocdetur se plantearon como objetivos: mejorar las finanzas municipales; dar atención directa a los prestadores de servicios turísticos y generar su participación con el gobierno municipal (Gaytán; 2004:73). Los fondos se manejaban mediante una cuenta bancaria exclusiva para este órgano y los integrantes decidían sobre su aplicación. Como puede apreciarse, dichos lineamientos no incluían una verdadera política de apoyo al turismo. Más bien, de acuerdo con la versión de algunos prestadores de servicios, Roberto San Román, heredero del Hotel Ixtapan era quien disponía qué hacer en beneficio de las empresas de su familia.

Con el paso del tiempo la principal inconformidad entre la mayoría de prestadores de servicios fue la escasa aplicación de los recursos en promoción y publicidad, que por el contrario se utilizaban para mejorar la infraestructura turística y la imagen urbana de la cabecera municipal y de los establecimientos de la referida familia (Ricaurte; 2001:123). Las discrepancias se agravaron cuando, según algunos prestadores de servicios, las autoridades excedieron sus gastos y casi a finales de la administración 2000-2003 usaron lo recaudado para atender diversas necesidades en otras comunidades. Esta serie de argumentos puede apreciarse en la tabla 1, que concentra las acciones que supuestamente se llevarían a cabo a partir de la creación del Consejo, y las que en realidad fueron realizadas. 


\begin{tabular}{|c|c|c|}
\hline Tabla No. 1 & Acciones propuestas & Acciones realizadas \\
\hline $\begin{array}{l}\text { Acciones y } \\
\text { propuestas } \\
\text { realizadas en el } \\
\text { Cocdetur }\end{array}$ & $\begin{array}{l}\text { - Analizar, discutir y proponer } \\
\text { obras y acciones relacionadas con } \\
\text { la ampliación y mejoramiento } \\
\text { de la infraestructura turística del } \\
\text { municipio. } \\
\text { - Deliberar y proponer al } \\
\text { H. Ayuntamiento la adopción, } \\
\text { modificación y eliminación de } \\
\text { disposiciones de la reglamentación } \\
\text { municipal y del Bando de Policía y } \\
\text { Buen Gobierno, relacionados con la } \\
\text { actividad turística. } \\
\text { - Promover, apoyar y organizar } \\
\text { eventos artísticos, culturales, } \\
\text { deportivos y recreativos cuyo } \\
\text { objeto sea incrementar la afluencia } \\
\text { turística en el municipio. } \\
\text { - Analizar y sugerir acciones } \\
\text { relacionadas con la imagen urbana, } \\
\text { particularmente señalizaciones, } \\
\text { fachadas, áreas verdes, etcétera. }\end{array}$ & $\begin{array}{l}\text { - Compra de vehículos y equipo } \\
\text { para mantener el boulevard Arturo } \\
\text { A. San Román e Ixtapan-Tonatico. } \\
\text { - Adquisición de equipo de } \\
\text { cómputo para las oficinas de } \\
\text { Desarrollo Económico, Turismo e } \\
\text { Ingresos. } \\
\text { - Compra de equipo de radio- } \\
\text { comunicación para la policía } \\
\text { municipal. } \\
\text { - Rehabilitación de alumbrado } \\
\text { público de la zona turística del } \\
\text { municipio, de la Unidad Deportiva y } \\
\text { del Jardín Central. } \\
\text { - Rehabilitación de alumbrado } \\
\text { público de jardines de la zona } \\
\text { turística. } \\
\text { - Elaboración y distribución tanto } \\
\text { de trípticos como de carteles de } \\
\text { promoción turística. }\end{array}$ \\
\hline
\end{tabular}




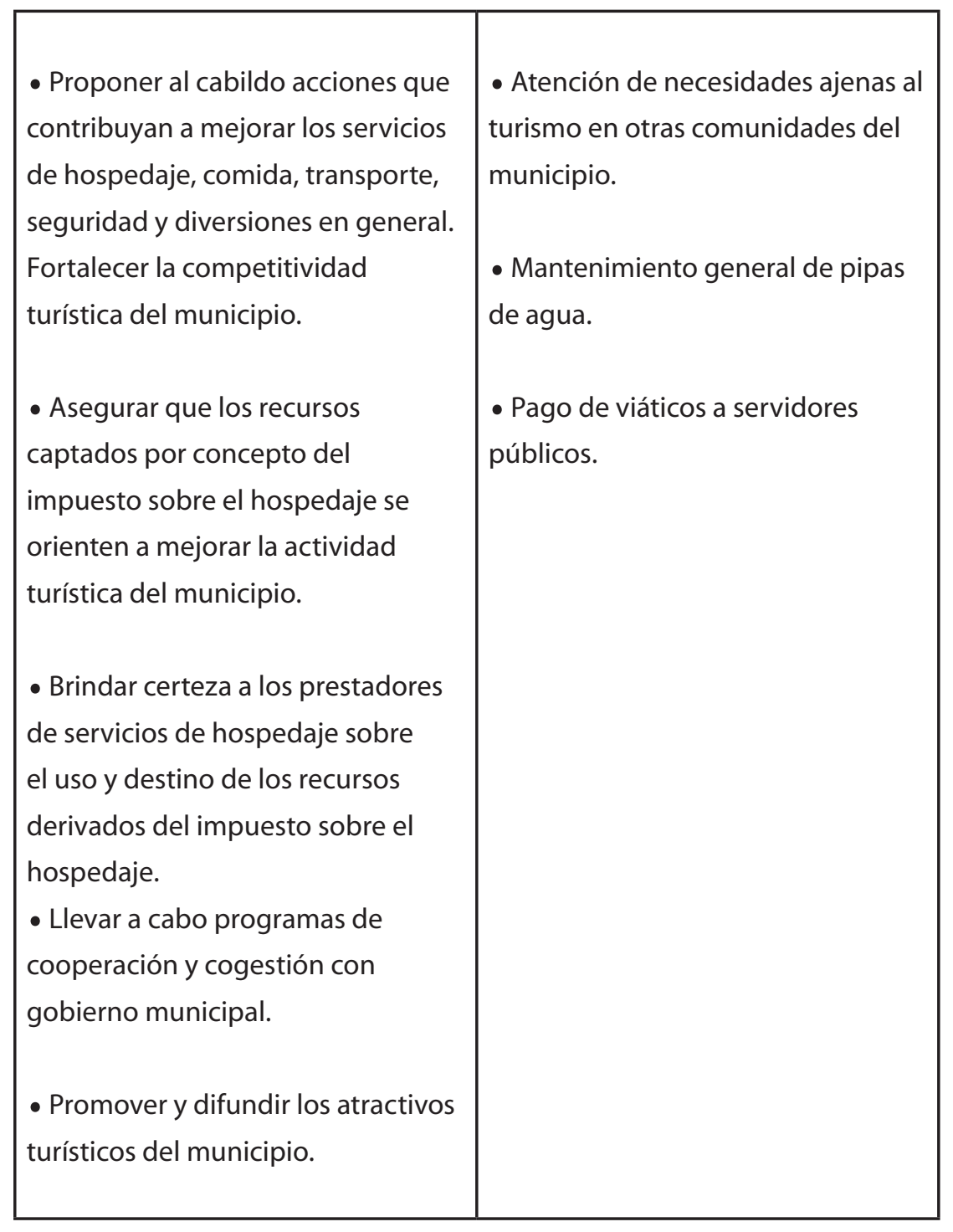

Fuente: Elaboración propia con base en Gaceta Municipal (2000:9); García y Gaytán (2001:49-50); Antecedentes de "El Consejo Consultivo de Desarrollo Turístico de Ixtapan de la Sal: unaexperiencia exitosa de democratización de la administración pública" (2001); EPN, 2005; GMN, 2005; LEMN, 2005. 
En la tabla anterior se evidencia cómo a pesar de que varias de las acciones realizadas son consecuentes con aquellas propuestas, algunas de éstas últimas no se llevaron a cabo y otras no tuvieron ningún vínculo con el renglón turístico. Tal situación originó el deterioro entre las relaciones de los empresarios con el Alcalde y fomentó el desinterés de seguir contribuyendo con esta obligación fiscal. Los prestadores de servicio más importantes dejaron de acudir a las sesiones; enviaban representantes o sólo acudían cuando tenían interés por tratar algún tema en particular (GMN, 2005; LEMN, 2005; EPN, 2005).

De igual forma, el Cocdetur no se hizo cargo de cuestiones tan importantes como la conservación de los recursos forestales de la localidad afectados en gran medida por el crecimiento urbano, producto de la construcción de fraccionamientos turístico-residenciales, situación que ha afectado sus recursos hidrológicos, así como la flora y fauna, que forman parte de su patrimonio. Los integrantes del Consejo concentraron sus acciones en atender cuestiones de servicios y promoción, las cuales fueron respaldadas por las autoridades municipales.

En este marco terminó la gestión del gobierno municipal 2000-2003 que tuvo una alta dependencia de la mayoría de los actores del sector privado pertenecientes al Coocdetur, porque éstos representaban la mayoría numérica y por lo tanto el proceso decisorio estuvo sujeto en gran medida a los acuerdos que emanaron de éstos, particularmente de los San Román.

Con el inicio de la administración 2003-2006 se registraron importantes modificaciones al interior del Consejo que fue reemplazado por la Junta Ejecutiva del Impuesto sobre el Hospedaje, cuya función estaba centrada en revisar la aplicación de dicho gravamen (NPG, 2005). Aún así, persistían varias de las inconformidades que los hoteleros venían expresando y se sumaron otras, con lo cual se alejó sensiblemente del propósito para el cual fue creado y quedaron pendientes algunos proyectos (EPN, 2005). Ese no sería el único cambio que sufriría dicho órgano, pues apenas un año después que el Cocdetur se transformó en Junta, ésta fue denominada -por acuerdo de Cabildo del 3 de noviembre de 2004-Comisión Ejecutiva del Impuesto sobre el Hospedaje. 
El propósito fue incrementar el número de integrantes del Ayuntamiento y evitar que los acuerdos sufrieran un doble análisis en su aprobación. Este último punto se derivó del hecho de que los acuerdos primero eran avalados en el Cocdetur donde participaba una minoría de funcionarios municipales y posteriormente se tenían que analizar de nuevo en asamblea de Cabildo, para su ratificación (CAAD, 2005), lo cual afectó en especial a los grandes empresarios que, como se refirió, orientaron las decisiones importantes en el Consejo. Un problema que enfrentó esta nueva figura fue cuando el Alcalde invitó a las reuniones a los pequeños hoteleros (HHP, 2005), lo cual generó descontento entre algunos prestadores de servicios, argumentando que las discusiones se volvieron lentas y dispersas. 


\section{ANTECEDENTES}

El Consejo Consultivo de Desarrollo Turístico, al menos en un principio, estuvo apegado al espíritu de las políticas públicas, pues su creación respondió a dos elementos que orientan la formación de dichas líneas de acción: 1) la detección de un problema por parte del sector público (la inconformidad por la aplicación del impuesto sobre el hospedaje) y 2) la formulación de una propuesta para atenderlo: el Cocdetur.

Pero, contrario al argumento del entonces presidente municipal Ignacio Rubí sobre la importancia de las organizaciones civiles en los Consejos (PMD, 2000:70) -lo cual representa otro elemento esencial de las políticas públicas- no incluyó a ningún actor del sector social que en su momento pudiera haber desempeñado un papel compatible con los propósitos de tales Consejos, o de cierta forma servir de contrapeso al predominio que ejerció el sector privado. Con ello, este órgano se alejó sensiblemente del perfil democratizador que el Alcalde se empeñó en darle, al menos en el papel y el sector privado resultó favorecido, provocando una relación asimétrica con el resto de sectores, lo que contraviene los principios de tales políticas.

Sin embargo lo más grave fue que con su propuesta para integrar el Cocdetur, el sector público se colocó a sí mismo en desventaja, pues permitió que el privado lo superara numéricamente, lo que impidió una representación equilibrada al interior de ese órgano y el ejercicio de contrapesos, por lo cual el sector público ajustó su actuación a las propuestas de los actores más poderosos, quienes condujeron la acción pública, por lo que el proceso decisorio estuvo marcadamente orientado hacia los intereses del sector privado. Roberto San Román Dunne pugnó en el seno de esta Comisión por posicionar en la agenda los asuntos que le permitieran cumplir sus objetivos y con ello atender sus intereses, centrados en consolidar el poderío económico y político de su familia.

Por lo tanto la supuesta pluralidad que debió prevalecer en ese órgano de consulta nunca existió, debido a la superioridad numérica del sector privado sobre el público, ya que el complejo proceso para formar la agenda estuvo supeditado a las negociaciones y a los conflictos en el seno del Cocdetur, mediante los cuales se definían los temas a discutir, la mayoría de veces centrados en el interés de los actores privados que siempre estuvieron a la vanguardia, lo que rompió el equilibrio que debería existir en un marco de política pública. 
En suma, esta serie de argumentos evidencia cómo el Cocdetur, que pudo haberse consolidado a raíz de una verdadera política pública, pues emanó de la autoridad municipal para atender una problemática, no pudo concretarse en acciones que atendieran de manera efectiva dicha problemática, ni alentó una participación incluyente o equitativa de los distintos sectores de la sociedad; tampoco benefició a la comunidad receptora que pocas veces es tomada en cuenta en el quehacer gubernamental y por lo tanto no es favorecida del turismo como en cambio sí lo son aquellos actores que logran imponer sus intereses e influir en la orientación de tal actividad, como se vio en este caso.

Lo mismo sucedió cuando el Cocdetur fue transformado en la Comisión Ejecutiva del Impuesto sobre el Hospedaje, a pesar del cambio de administración municipal que hubo entre uno y otro órgano, lo que podría traducirse en una inercia. La creación de este nuevo órgano respondió, en efecto, a una problemática aunque no social, sino del sector privado y específicamente tanto de los grandes hoteleros como de Roberto San Román Dunne, representante del Hotel Ixtapan, es decir, de los actores más poderosos en términos económicos y de influencia política, aunque el propósito de la formación de ese nuevo órgano favoreció además, pero de manera más indirecta, a los medianos prestadores del servicio de hospedaje.

Esta situación puede explicarse a partir de que el gobierno municipal utilizó sus facultades como autoridad pública en beneficio del sector privado, ya que desde un principio pudo haber utilizado sus atribuciones para que el sector público se erigiera en términos cuantitativos como el más importante al interior de la Comisión y no fue así, pues además que de nueva cuenta se encontró en desventaja numérica frente a los empresarios, su afán por integrar a más funcionarios municipales estuvo encaminado a legitimar los acuerdos que se tomaban en este órgano y así beneficiar a los empresarios, por lo que no estuvo alentado por un verdadero afán de propiciar una representación equitativa.

Las autoridades municipales tuvieron la oportunidad y, no lo hicieron, de mejorar el desempeño de su función en dos momentos: la creación del Cocdetur y en su reestructuración en una Comisión, que pudieron haber servido como órganos eficaces de participación ciudadana, acorde con el 
propósito inicial -al menos en el papel- del Consejo, ya que independientemente de la consulta sobre los asuntos turísticos, habría propiciado la participación de los representantes de los sectores público, social y privado y de esta manera alentar un proceso decisorio más participativo, comprometido, corresponsable y equitativo.

Con ello se corrobora que más que políticas públicas, el Ayuntamiento ixtapense detentó su autoridad para establecer acciones de gobierno mediante el Cocdetur en cuya integración no participaron quienes formarían parte de él; su implementación y el manejo de sus recursos no fueron transparentes, pues tendieron a favorecer los intereses de unos cuantos actores, lo cual lo alejó de proyectos de alcance general, para volverlos particulares.

Por lo tanto la actuación de las autoridades no contribuyó a fomentar la democracia, la pluralidad y la corresponsabilidad, entre otros valores impulsados por las políticas públicas. Por el contrario, alentó la desconfianza y los cuestionamientos sobre su conducción, apartada de los principios de tales líneas de acción.

De esta forma, las autoridades municipales perdieron la oportunidad de formar un verdadero órgano de consulta con participación equilibrada entre los diferentes sectores para que encaminaran su actuación a procurar condiciones de equidad, no solamente de ventaja para aquellos con mayores recursos y posibilidades de imponer su juego político y con ello hacer prevalecer sus objetivos e intereses, en detrimento del resto y sin posibilitar además condiciones sustentables para la comunidad receptora, tendientes a elevar su calidad de vida de sus habitantes y procurar condiciones de equidad, haciéndolos partícipes desde un principio en las distintas fases de planeación, visualizando objetivos a futuro para sus habitantes (Cruz; 2002:18). 


\section{BIBLIOGRAFÍA}

- Aguilar Villanueva, Luis F. (1992), El estudio de las políticas públicas. Estudio introductorio y edición, Colección Antologías de Política Pública, Miguel Ángel Porrúa, México.

- Arizmendi Domínguez, Luis René (1999 A), Monografía Municipal Ixtapan de la Sal, Gobierno del Estado de México, Asociación Mexiquense de Cronistas Municipales: Toluca, México.

- Bazúa, Fernando y Valenti, Giovanna (1994) "Política Pública y desarrollo", Políticas públicas y desarrollo municipal. Problemas teórico-prácticos de la gestión pública municipal, El Colegio Mexiquense, A.C/ Universidad Autónoma del Estado de México: Zinacantepec, pp. 48-59.

- Cabrero Mendoza, Enrique, coord. (2003), Políticas públicas municipales. Una agenda en construcción, CIDE-Miguel Ángel Porrúa: México.

- - (2000), Usos y costumbres en la hechura de las políticas públicas en México. Límites de las policy sciences en contextos cultural y políticamente diferentes, Gestión y Política Pública, CIDE, Vol. IX, núm. 2, segundo semestre de 2000, pp. 189-276.

- Cruz Jiménez, Graciela (2002) Turismo sustentable y sistemas complejos en San Miguel Almaya, Méx, Tesis, Facultad de Turismo, UAEM: Toluca.

- Flores Mercado, Arturo (1987), Monografía municipal Ixtapan de la Sal, Gobierno del Estado de México, Toluca, México.

- García del Castillo, Rodolfo (1994), "Las políticas de servicios municipales", "Políticas públicas y desarrollo municipal. Problemas teórico-prácticos de la gestión pública municipal", El Colegio Mexiquense, A.C/ Universidad Autónoma del Estado de México, pp. 38-51.

- García del Castillo, Rodolfo y Gaytán Olmedo, Soledad (2001), "Consejo consultivo para el desarrollo turístico de Ixtapan de la Sal : una experiencia exitosa de democratización de la administración pública municipal", en Cabrero, Enrique (coord.) Innovación en gobiernos locales: Un panorama de experiencias municipales en México, CIDE: México, pp. 45-61.

- García Mendoza, Jaime (2000), Iztapan en el siglo XVI, Ixtapan de la Sal, Cuadernos Municipales, No. 16, El Colegio Mexiquense: Zinacantepec, México pp. 31-70.

- Gaytán Olmedo, María Soledad (2004), "El Consejo Consultivo para el Desarrollo Turístico de Ixtapan de la Sal", Páramo del Campo y la Ciudad, Centro de Estudios sobre Marginación y Pobreza del Estado de México, Año 2., Núm. 6, diciembre 2004, pp. 68-74. 
- Gobierno del Estado de México (2003), Plan Municipal de Desarrollo Urbano de Ixtapan de la Sal.

- ------ (2000), Gaceta Ixtapan de la Sal. Año. 1 Núm. 2. Plan de Desarrollo Municipal 2000-2003. (2000), Código Financiero del Estado de México y Municipios, México. (1993), Ley Orgánica Municipal del Estado de México. Toluca.

- González Damián, Alfonso (2004), "El anfitrión como actor social en el turismo. Reflexiones desde el caso de Ixtapan de la Sal, México". Revista de Ciencias Sociales (cr), año/ Vol. III, número 105. Universidad de Costa Rica, San José Costa Rica, pp 155168.

- H. Ayuntamiento de Ixtapan de la Sal (2001), Antecedentes de "El Consejo Consultivo de Desarrollo Turístico de Ixtapan de la Sal: una experiencia exitosa de democratización de la administración pública". Propuesta presentada ante el Centro de Investigación y Docencia Económicas (CIDE) para ser considerada en el Premio Anual 2001 de "Gobierno y Gestión Local".

- H. Ayuntamiento de Ixtapan de la Sal (2001), Antecedentes de "El Consejo Consultivo de Desarrollo Turístico de Ixtapan de la Sal: una experiencia exitosa de democratización de la administración pública". Propuesta presentada ante el Centro de Investigación y Docencia Económicas (CIDE) para ser considerada en el Premio Anual 2001 de "Gobierno y Gestión Local".

- H. Ayuntamiento de Ixtapan de la Sal (2000, 2001), Cuenta del Consejo Consultivo para el Desarrollo Turístico de Ixtapan de la Sal. Control de chequera.

- H. Ayuntamiento de Ixtapan de la Sal (2001), Actas de las sesiones 6, 7, 8, 9, 10, 11 y 12 del Consejo Consultivo de Desarrollo Turístico de Ixtapan de la Sal, así como de dos extraordinarias. 15 de enero, 12 de febrero, 19 de marzo, 23 de abril, 22 de mayo, 30 de mayo, 25 de junio, 9 de julio y 7 de agosto de 2001.

- H. Ayuntamiento de Ixtapan de la Sal (2000), Gaceta. Año 1, Núm. 1, 18 de octubre de 2000.

- Lasswell, Harold D. (1951), "La orientación hacia las políticas", El estudio de las políticas públicas, Porrúa, México.

- Lickorish, Leonard J, y Jenkins, Carson (1997), Una introducción al turismo. Síntesis, Madrid. 
- Martínez, Juan Manuel (1997), El esquema laboral del turismo en Ixtapan de la Sal. Tesis, Facultad de Turismo" UAEM, Toluca, México.

- Méndez, José Luis (1993), "La política pública como variable dependiente: Hacia un análisis más integral de las políticas públicas", Lecturas básicas de administración y políticas públicas, El Colegio de México: México, pp. 75-102.

- ----------- (1994), "El campo de las políticas públicas: promesas y peligros", Políticas públicas y desarrollo municipal. Problemas teórico-prácticos de la gestión pública municipal, El Colegio Mexiquense, A.C/ Universidad Autónoma del Estado de México, pp. 48.72.

- Meny, Ives y Thoenig Jean-Claude (1992), Las políticas públicas. Ariel, Barcelona.

- Merino, Mauricio (2000), "De una disciplina sin objeto de estudio, a un objeto de estudio sin disciplina. Administración y políticas públicas desde una perspectiva nacional", Lecturas básicas de administración y políticas públicas, El Colegio de México, Centro de Estudios Internacionales: México, pp. 38-45.

- Meyer, Lorenzo (1994), "El municipio mexicano al final del Siglo XX. Historia, obstáculos y posibilidades", En busca de la democracia municipal: La participación ciudadana en el gobierno local mexicano, El Colegio de México: México, pp. 231-251.

- Organización Mundial del Turismo (2002), Guía para las administraciones locales: desarrollo turístico sostenible. Madrid.

- Ricaurte Quijano, Carla (2001), Turismo, sustentabilidad y gestión local en el municipio de Ixtapan de la Sal, Tesis, Facultad de Turismo, UAEM, Toluca, México.

- Rodríguez, Victoria E. (1999), La descentralización en México. De la reforma municipal a Solidaridad y el nuevo federalismo, Fondo de Cultura Económica, México.

- Secretaría de Recursos Hidráulicos (1947), Título de concesión Número 21 . México.

- Secretaría de Turismo (2005), "Comportamiento del movimiento turístico por lugar".

- Uvalle Berrones, Ricardo (1997), Las políticas públicas: Un testimonio del gobierno ilustrado y democrático. Políticas públicas: actualidad y perspectivas. Num. 35 julioseptiembre 1997. Instituto de Administración Pública del Estado de México, Toluca, México. 


\section{RECURSOS ELECTRÓNICOS}

- Universidad Autónoma de Guadalajara (2003), "Nuevo modelo mexicano de clasificación y certificación de hoteles". www.uag.mx (Consulta: 21/03/2005).

\section{ENTREVISTAS REALIZADAS}

\begin{tabular}{|l|c|l|}
\hline \multicolumn{1}{|c|}{ NOMBRE } & INICIALES & \multicolumn{1}{|c|}{ CARGO } \\
\hline Cesáreo Antonio Domínguez Díaz & CADD & Presidente municipal 2003-2006 \\
\hline Hugo Hernández Puga & HHP & $\begin{array}{l}\text { Regidor comisionado de Turismo y } \\
\text { Recreación 2003-2006 }\end{array}$ \\
\hline Luis René Domínguez Arizmendi & LRDA & Cronista \\
\hline Noemí Pérez González & NPG & Directora de Turismo 2003-2006 \\
\hline Javier Madrid Hernández & JMH & $\begin{array}{l}\text { Presidente Comité Ejecutivo } \\
\text { Municipal del PRD }\end{array}$ \\
\hline Julio César Sergio Becerril Román & JCSBR & $\begin{array}{l}\text { Ex candidato del PAN a la presidencia } \\
\text { municipal 2003-2006 }\end{array}$ \\
\hline Raúl Domínguez Estrada & RDE & Propietario Hotel Ideal \\
\hline Gerardo Morán Noreña & GMN & Gerente Bungalows Lolita \\
\hline Luis Enrique Morán Noreña & LEMN & Administrador Bungalows Lolita \\
\hline Israel Aldrete Espiniella & IAE & Propietario Hotel Avenida \\
\hline Enrique Pérez Nájera & EPN & Gerente Hotel Belisana \\
\hline
\end{tabular}


CITAS

' Según el enfoque de política pública de Lasswell (1951:83), el concepto de política (policy está libre de connotaciones indeseables implícitas en la palabra política (politics) que se concentra básicamente en cuestiones partidistas (Meny y Thoenig; 1992:89) y que con frecuencia se asocia con "partidarismo" o "corrupción".

${ }^{2}$ En cualquiera de sus ámbitos: federal, estatal o municipal, para el caso mexicano.

${ }^{3}$ La referencia a una entrevista se hizo consignando las iniciales del actor que otorgó su testimonio y el año en que se efectuó dicha entrevista. Es preciso destacar que se dificultó obtener el testimonio de ciertos actores (el caso de los propietarios de Del Rey Inn y de Rancho San Diego), mientras otros se negaron a ser entrevistados. Es de resaltar que quienes rechazaron dar su testimonio fueron algunos protagonistas del turismo en Ixtapan de la Sal: Arturo y Roberto San Román Widerkehr, hijos del patriarca de la familia, así como los descendientes de éstos, Arturo San Román Moore, Ricardo y Roberto San Román Dunne. De la misma forma el restaurantero Eduardo Beltrán, y el ex alcalde Ignacio Rubí Salazar, quienes han sido cuestionados por su cercanía con la familia San Román.

${ }^{4}$ Los autores utilizan el término publiceidad para referirse al carácter o naturaleza pública del Estado, de las instituciones públicas y/o de las decisiones, acciones y políticas gubernamentales.

${ }^{5}$ Modelo en cuanto a representación de una realidad, en este caso de una realidad turística.

${ }^{6}$ En lo sucesivo se designará PMD a los Planes Municipales de Desarrollo a que se haga referencia.

7 El INEGI incluye en este sector al comercio, transporte, comunicaciones y servicios (en este último se inserta el turismo).

${ }^{8}$ Así se le denominó a la primera región minera de la Nueva España, conformada por cuatro comarcas: Temazcaltepec, Sultepec, Zacualpan y Tasco. Ixtapan era un poblado perteneciente a la comarca de Zacualpan (García, 2000:31).

9 Desde 1960 y hasta 2005 la Comisión Nacional de Agua (CNA) había otorgado 13 concesiones de este recurso: 11 a comunidades del municipio, otra a NISA y una más al Organismo Público Descentralizado de Carácter Municipal para la Prestación de los Servicios de Agua Potable, Alcantarillado y Saneamiento de Ixtapan de la Sal (Odapas). 
10 En 1998 el gobernador César Camacho Quiroz y el titular de la Sectur, Óscar Espinosa Villareal inauguraron los juegos del Parque. Los servicios con que cuenta en sus 35 hectáreas son: aguas termales con su borbollón en la alberca cubierta a $38^{\circ} \mathrm{C}$ y en una descubierta a $32^{\circ} \mathrm{C}$. Estas aguas se encuentran a $29^{\circ} \mathrm{C}$ en una alberca olímpica y en un chapoteadero, ubicadas en el área exterior del balneario tradicional. Funcionan tres trenecitos, réplicas del célebre C.P Huntington de 1863, que realizan un recorrido escénico por el parque. También dispone de área de asadores, mirador, canchas deportivas, embarcadero, carrusel. Entre los juegos destacan resbaladillas, cañones y juegos acuáticos, tobogán de 150 metros, albercas con toboganes y resbaladillas, río y alberca con olas, así como tobogán con bajadas múltiples, entre otros.

11 Hasta 1994 la Sectur clasificaba los establecimientos de hospedaje. A mayor cantidad y calidad de servicios se le otorgaban hasta cinco estrellas, aunque lvego fueron incorporadas otras categorías como "gran turismo". Con la firma del Tratado de Libre Comercio (TLC), el gobierno mexicano dejó de funcionar como órgano regulador de la calidad en productos y servicios, limitando su ámbito de competencia a regir únicamente los reglamentos técnicos de seguridad. Una vez desligadas las normas de seguridad y calidad, esta última requirió de organismos independientes que sugirieran parámetros de calidad en la operación de servicios de la hotelería, surgiendo así Calidad Mexicana Certificada A.C. (CALMECAC), acreditado como el primer organismo nacional de certificación reconocido internacionalmente. No obstante, algunos establecimientos de hospedaje siguen usando la referida clasificación (www.vag.mx).

${ }^{12}$ De acuerdo con el Código Financiero del Estado de México y Municipios (2000:265) están obligadas a pagar dicho impuesto las personas físicas y morales que presten este servicio mediante hoteles, moteles, albergues, posadas, hosterías, mesones, campamentos, paraderos de casas rodantes, tiempos compartidos y otros establecimientos de esta naturaleza. Su monto se determina aplicando la tasa de $3 \%$ sobre el total de la contraprestación por este tipo de servicio.

${ }^{13}$ Antecedentes de "El Consejo Consultivo de Desarrollo Turístico de Ixtapan de a Sal: una experiencia exitosa de democratización de la administración pública" (2001), propuesta presentada ante el Centro de Investigación y Docencia Económicas (CIDE) para ser evaluada en el marco del Premio Anual 2001 de "Gobierno y Gestión Local". 


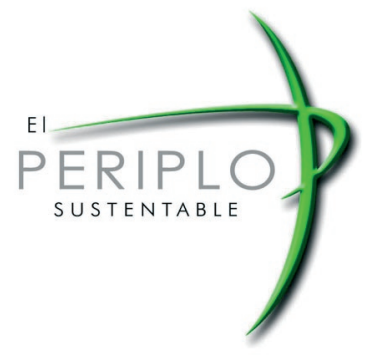

FICHA BIBLIOGRÁFICA:

Cruz-Jiménez, G. ¿Políticas públicas o acciones de gobierno turísticas en Ixtapan de la Sal? El caso del Cocdetur.

El Periplo Sustentable. Espacio de análisis y reflexión sobre Turismo Sustentable. México: Universidad Autónoma del Estado de México, enero de 2008, núm. 13

$<$ http://www.uaemex.mx/plin/psus/rev13/articulo_01.pdfs. [ISSN: 1870-9036]. 